\title{
Estradiol regulates GH-releasing peptide's interactions with GH-releasing hormone and somatostatin in postmenopausal women
}

\author{
Catalina Norman, Nanette L Rollene ${ }^{1}$, Dana Erickson, John M Miles, Cyril Y Bowers ${ }^{2}$ \\ and Johannes D Veldhuis \\ Endocrine Research Unit, Mayo School of Graduate Medical Education, Center for Translational Science Activities, \\ Mayo Clinic, Rochester, Minnesota 55905, USA, 'Division of Reproductive Endocrinology, Naval Medical Center \\ Portsmouth (NMCP), Portsmouth, Virginia 23708, USA and ${ }^{2}$ Endocrinology and Metabolism Section, Peptide \\ Research Section, Tulane University Health Sciences Center, New Orleans, Louisiana 70112, USA
}

\author{
Correspondence \\ should be addressed \\ to J D Veldhuis \\ Email \\ veldhuis.johannes@mayo.edu
}

\begin{abstract}
Objective: Estrogen stimulates pulsatile secretion of $\mathrm{GH}$, via mechanisms that are largely unknown. An untested hypothesis is that estradiol $\left(E_{2}\right)$ drives $\mathrm{GH}$ secretion by amplifying interactions among GH-releasing hormone (GHRH), somatostatin (SS), and GH-releasing peptide (GHRP).

Design: The design comprised double-blind randomized prospective administration of transdermal $\mathrm{E}_{2}$ vs placebo to healthy postmenopausal women $(n=24)$ followed by pulsatile GHRH or SS infusions for $13 \mathrm{~h}$ overnight with or without continuous GHRP2 stimulation.

Methods: End points were mean concentrations, deconvolved secretion, and approximate entropy (ApEn; a regularity measure) of $\mathrm{GH}$.

Results: By generalized ANOVA models, it was observed that $\mathrm{E}_{2}$ vs placebo supplementation: i) augmented mean (13-h) $\mathrm{GH}$ concentrations $(P=0.023)$, GHRH-induced pulsatile $\mathrm{GH}$ secretion over the first $3 \mathrm{~h}(P=0.0085)$ and pulsatile $\mathrm{GH}$ secretion over the next $10 \mathrm{~h}(P=0.054)$; ii) increased GHRP-modulated $(P=0.022)$ and SS-modulated $(P<0.001) \mathrm{GH}$ ApEn; and iii) did not amplify GHRH/GHRP synergy during pulsatile $\mathrm{GH}$ secretion. By linear regression, $E_{2}$ concentrations were found to be positively correlated with GH secretion during GHRP2 infusion $(P=0.022)$, whereas BMI was found to be negatively correlated with $\mathrm{GH}$ secretion during GHRH $(P=0.006)$ and combined GHRH/GHRP $(P=0.015)$ stimulation. $\mathrm{E}_{2}$ and $\mathrm{BMI}$ jointly determined triple (combined L-arginine, GHRH, and GHRP2) stimulation of GH secretion after saline $\left(R^{2}=0.44\right.$ and $\left.P=0.003\right)$ and pulsatile GHRH $\left(R^{2}=0.39\right.$ and $\left.P=0.013\right)$ infusions.

Conclusion: In summary, in postmenopausal women, $E_{2}$ supplementation augments the amount (mass) and alters the pattern (regularity) of GH secretion via interactions among GHRH, SS, GHRP, and BMI. These outcomes introduce a more complex model of $\mathrm{E}_{2}$ supplementation in coordinating $\mathrm{GH}$ secretion in aging women.
\end{abstract}

\section{Introduction}

Decreased growth hormone (GH) secretion during aging, hypogonadism, and obesity was recognized almost four decades ago $(1,2,3,4)$. Low GH concentrations, in turn, are associated with insulin resistance, dyslipidemia, cardiovascular mortality, sarcopenia, osteopenia, possible cognitive impairment, and reduced quality of life. Supplementation of estradiol $\left(\mathrm{E}_{2}\right)$ in girls or women and that of an aromatizable androgen in boys or men stimulate GH production and alter the regularity of GH secretion patterns $(2,3,5)$. The importance of $E_{2}$ is inferable in both sexes,
(C) 2014 European Society of Endocrinology Printed in Great Britain
Published by Bioscientifica Ltd. 
since an ER antagonist lowers GH concentrations in women and men and an aromatase inhibitor blocks $\mathrm{GH}$ responses to testosterone in men $(2,3,6)$. Nonetheless, the precise clinical mechanisms mediating estrogen's augmentation of $\mathrm{GH}$ secretion remain largely unknown.

The effects of gonadal estrogen on the GH axis have been investigated in animal models by ovariectomy and transgenic silencing of the ER $\alpha$ (ESR1) and aromatase genes $(2,3,7)$. In rats, $\mathrm{E}_{2}$ controls hypothalamic GH-releasing hormone (GHRH) neurons, hypothalamic receptors for GH-releasing peptide (GHRP), pituitary receptors for GHRH and GHRP, somatostatin (SS) receptor subtypes 2 and 5, and gastric ghrelin (native GHRP) expression $(2,3,7)$. The various effects of $E_{2}$ on $G H R H$, SS, and ghrelin secretion and action in animal models strongly suggest the estrogenic control of multiple peptide pathways. However, to date, available clinical studies of $\mathrm{E}_{2}$ action have evaluated primarily single-peptide effects, rather than their interactions. To address this major limitation, the present study combined: i) experimental imposition of young-adult $\mathrm{E}_{2}$ concentrations in postmenopausal women; ii) individual and combined infusions of hypothalamic peptides (GHRH, SS, and GHRP) for $13 \mathrm{~h}$ overnight; iii) deconvolution (secretion-based) and approximate entropy (ApEn, a pattern-regularity measure) analyses of $\mathrm{GH}$ concentration-time series; and iv) triple stimulation of $\mathrm{GH}$ secretion with L-arginine and GHRH/GHRP to estimate maximal (pharmacological) pituitary GH secretory capacity. The end points are important, because burst-like (pulsatile) GH secretion and ApEn-quantified secretion regularity are physiologically supervised modes of GH secretion $(2,3,8)$. The postulate was that both the amount and pattern of $\mathrm{GH}$ secretion are jointly specified by $\mathrm{E}_{2}, \mathrm{GHRH}, \mathrm{GHRP} /$ ghrelin, and SS, along with BMI as a surrogate of relative adiposity.

\section{Subjects and methods}

\section{Study design and volunteers}

The study protocol was approved by the Mayo Institutional Review Board (IRB) and reviewed by the U.S. Food and Drug Administration. This was a double-blind, placebocontrolled, prospectively randomized study of 24 healthy, community-based, ambulatory women conducted in the Center for Translational Science Activities (CTSA). The subjects were healthy postmenopausal women (folliclestimulating hormone (FSH) levels $>30 \mathrm{IU} / \mathrm{l}$ and $\mathrm{E}_{2}$ levels $<50 \mathrm{pmol} / \mathrm{l}$ ) in the allowable age range of $50-80$ years. The subjects provided witnessed voluntary informed consent approved by the Mayo IRB. Screening consisted of medical history, physical examination, and biochemical testing. Eligibility required normal hepatic, renal, hematological, metabolic, and endocrine function and a negative mammogram within the last 12 months. Exclusion criteria were hypopituitarism, hyperthyroidism, hyperprolactinemia, concurrent use of neuroactive medications or sex hormones, acute or chronic systemic illness, diabetes mellitus, weight loss ( $>2 \mathrm{~kg}$ ) in the last 3 months, systemic inflammatory disease, BMI $<20$ or $>32 \mathrm{~kg} / \mathrm{m}^{2}$, greater than three time-zone transmeridian travel in the last week, shift-work schedule, concurrent involvement in any other study, drug or alcohol abuse, hemoglobin levels $<2 \mathrm{~g} / \mathrm{dl}$, thrombotic arterial disease (stroke, transient ischemic attack (TIA), myocardial infarction (MI), and angina), pulmonary embolism or thrombophlebitis, and history or suspicion of cancer or neoplasm (except for basal cell carcinoma if localized and treated surgically).

\section{$E_{2}$ treatment}

$\mathrm{E}_{2}$ supplementation was via daily transdermal $\mathrm{E}_{2}$ patches (Novartis) at escalating increasing doses, viz. $0.05 \mathrm{mg} /$ day (184 nmol) for the first 4 days, $0.10 \mathrm{mg} /$ day $(368 \mathrm{nmol})$ for the next 4 days, and $0.15 \mathrm{mg} /$ day $(552 \mathrm{nmol})$ for 20 additional days (9). Overnight infusion studies were initiated after at least 4 days on the highest $(0.15 \mathrm{mg}) \mathrm{E}_{2}$ dose. Medroxyprogesterone acetate ( $5 \mathrm{mg}$; Pharmacia and Upjohn, New York, NY, USA) was given orally daily for 12 days after $\mathrm{E}_{2}$ supplementation, when all infusion/ sampling sessions were completed.

\section{Sampling schedule}

The participants were admitted to the CTSA by $1530 \mathrm{~h}$ on the evening of the study. To limit nutritional confounds, a standardized meal $(33 \mathrm{~kJ} / \mathrm{kg}$ of $50 \%$ carbohydrate, $20 \%$ protein, and 30\% fat) was served at $1600 \mathrm{~h}$. The subjects then remained fasting, alcohol abstinent, and caffeine free until noon the next day. Vigorous exercise and daytime sleep were not allowed. Bilateral cannulas were placed in forearm veins at or before $1900 \mathrm{~h}$ to permit concurrent overnight blood sampling and peptide infusions.

\section{Infusion and sampling paradigm}

Each subject participated in a total of six (6) separate randomly ordered double-blind overnight consecutive 13- and 3-h (total 16-h) infusion sessions (2000 h until noon the next day) scheduled at least $48 \mathrm{~h}$ apart in the 
CTSA (Fig. 1). Three infusion sessions comprised continuous i.v. saline infusions $(30 \mathrm{ml} / \mathrm{h})$ and the other three sessions comprised continuous i.v. GHRP2 infusions ( $1 \mu \mathrm{g} / \mathrm{kg}$ per $\mathrm{h})$ for $13 \mathrm{~h}(2000-0900 \mathrm{~h})$. Based upon prior dose-response curves obtained in older women $(10,11$, 12), bolus i.v. saline (Sal; $1 \mathrm{ml})$, GHRH $(1.0 \mu \mathrm{g} / \mathrm{kg})$, or SS $(0.67 \mu \mathrm{g} / \mathrm{kg})$ pulses were superimposed upon the continuous saline or GHRP2 infusions every $90 \mathrm{~min}$ for a total of nine pulses during the inclusive time window 20000850 h. GHRP2 was obtained from Kaken Pharmaceuticals (Tokyo, Japan), and GHRH and SS were obtained from Bachem Laboratories (Torrance, CA, USA).

Immediately after the $13-\mathrm{h}$ overnight pulsatile peptide infusions, a triple secretagogue was administered, followed by three more hours of sampling. This was done to test maximal (pharmacological) GH release. The triple stimulus comprised sequential i.v. infusion of L-arginine (30 g continuously from 0900 to $0930 \mathrm{~h}$ ). This was immediately followed by combined bolus injections of

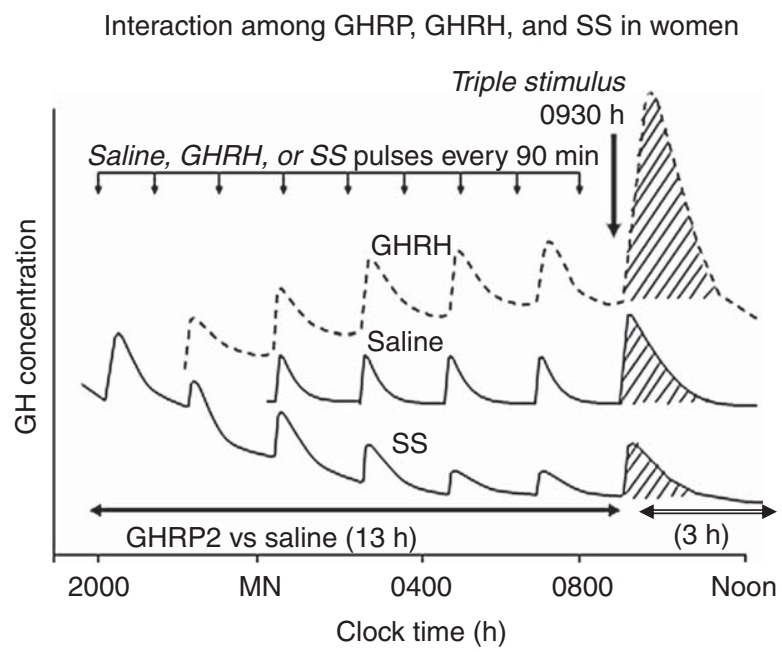

\section{Figure 1}

Schematic representation of 16-h overnight peptide infusion/ blood sampling protocol conducted in 24 postmenopausal women randomized to 20 days of transdermal $\mathrm{E}_{2}$ or placebo (PI) exposure. During $\mathrm{E}_{2}(n=10)$ or $\mathrm{PI}(n=14)$ exposure, each subject participated in six randomly ordered 13-h i.v. infusion sessions with overnight fasting: three with continuous saline stimulation and three with continuous GHRP2 stimulation. Pulses of saline (Sal), GHRH, or SS were superimposed every 90 min i.v. during the 13-h infusion sessions. Sampling was continued for an additional $3 \mathrm{~h}$ to test pituitary $\mathrm{GH}$ secretory capacity using a triple-secretagogue stimulus (consecutive L-arginine and bolus GHRH/GHRP2 injections).
GHRH and GHRP2 (both i.v. at $1.0 \mu \mathrm{g} / \mathrm{kg}$ ) at $0930 \mathrm{~h}$. This combination has been used by others (8).

Blood ( $0.75 \mathrm{ml} / \mathrm{sample})$ was withdrawn every $10 \mathrm{~min}$ for $16 \mathrm{~h}$ (2000 h-noon) from all 24 subjects during all the six sessions. Sleep was not assessed in this study. Serum that was separated was frozen at $-70^{\circ} \mathrm{C}$ until assay.

\section{Assays}

GH concentrations were determined as a batch of 582 samples/subject via a robotics-assisted two-site monoclonal immunoenzymatic chemiluminescence assay (sensitivity $0.010 \mu \mathrm{g} / \mathrm{l}$ ). The assay standard was $22 \mathrm{kDa}$ recombinant human GH. Inter-assay coefficients of variation (CV) for $\mathrm{GH}$ concentrations of 3.4 and $12 \mu \mathrm{g} / \mathrm{l}$ were 7.9 and $6.3 \%$ respectively. Intra-assay $\mathrm{CV}$ values for $\mathrm{GH}$ concentrations of 1.1 and $20 \mu \mathrm{g} / 1$ were 4.9 and $4.5 \%$ respectively. No values were $<0.020 \mu \mathrm{g} / \mathrm{l}$. Screening thyroid-stimulating hormone (TSH), prolactin, luteinizing hormone (LH), and FSH concentrations were quantified by an automated chemiluminescence assay (ACS 180; Bayer), using as standards recombinant TSH and prolactin and the First and Second International Gonadotropin Reference Preparations. Liquid chromatography-tandem mass spectrometry was used to quantify $\mathrm{E}_{2}$ and testosterone concentrations in serum samples collected at $0800 \mathrm{~h}$ at screening and at each of the six (6) CRU visits (13). SHBG, insulin-like growth factor 1 (IGF1), IGF-binding protein 1 (IGFBP1), and IGFBP3 concentrations were assayed by an immunoradiometric assay (Diagnostic Systems Laboratories, Webster, TX, USA).

\section{Analytical methods}

Deconvolution analysis was applied to the initial 3-h (2000-2250 $\mathrm{h}$ inclusive) and the next 10-h (2300-0900 h) windows of the $13 \mathrm{~h}$ of $10-\mathrm{min}$ sampling sessions during peptide/saline infusions, as well as to the final $3 \mathrm{~h}$ (0900 h-noon) of 10-min sampling sessions during the triple stimulus. The goal was to estimate basal (nonpulsatile) and pulsatile (burst-like) GH secretion and thereby total GH secretion. The first 3-h GH responses to peptide infusions (2000-2250 h) were used to estimate readily releasable $\mathrm{GH}$ (14). GH secretion was quantified using published biexponential GH-elimination kinetics (viz. 3.5- and 20.8-min half-lives (15)). The Matlab model is conditioned mathematically on a priori identification of candidate sets of pulse-onset times using an image boundary-detection technique. Pulse number is optimized by the Akaike information criterion (16). Both sensitivity and specificity are $93 \%$. 


\section{Approximate entropy}

ApEn (1, 20\%) was used as a scale- and model-independent statistic to quantify the relative orderliness (regularity) vs disorderliness (irregularity). Higher ApEn denotes greater relative randomness (irregularity) of the secretion process. Mathematical models and clinical experiments establish that greater irregularity signifies decreased feedback control with high sensitivity and specificity (both >90\%) (17).

\section{Biostatistical analysis}

The experimental design was consistent with the general principles of a split-plot design. The whole plots were the primary treatments of $E_{2}$ or placebo. Within each condition, the participants received six different infusions (GHRP2 vs Sal infusion crossed with Sal, GHRH, or SS infusion). The nesting of the treatments within patients was addressed statistically by means of a mixed fixed- and random-effects model using SAS PROC MIXED. Main effects for each level of the split-plot design along with their two- and three-variable interactions were modeled as fixed effects. The random effect consisted of a random participant (blocking) factor. To limit heterogeneity of variance, parameters were first log-transformed. Modelbased means were compared with the Tukey-Kramer post hoc correction factor. The degrees of freedom for the fixed effects were estimated using the Kenward-Roger method. Experiment-wise (adjusted) $P$ values $<0.05$ were considered statistically significant, except for multiple comparisons when $P<0.01$ (protected) was used (18). Post hoc analysis used Tukey's honestly significantly different (HSD) test. Analyses were conducted using the SAS System, version 9.3 (Cary, NC, USA).

Epidemiological data are presented as means \pm s.E.M. (medians and ranges) to provide a full view of variability. Backward stepwise-elimination linear regression was carried out to identify the independent or joint contributions of IGF1, IGFBP1, IGFBP3, and $\mathrm{E}_{2}$ concentrations and/or BMI to the modulation of GH production.

\section{Statistical power}

By way of statistical power estimates, earlier studies had quantified pulsatile GH secretion stimulated by: i) 90-min pulses of GHRH in 19 men; ii) continuous i.v. infusion of GHRH and/or GHRP2 in 12 women; and iii) i.v. injections of SS in 11 other women (10). On combining these studies, the respective amplifying actions of $\mathrm{E}_{2}$ and GHRH were
$2.1 \pm 0.18$ (s.D.) and $4.9 \pm 0.53$-fold placebo/saline; the effect of GHRP2 was $8.5 \pm 2.2$-fold saline; and the effect of SS suppression was $0.5 \pm 0.11$-fold saline $(5,10,11,12)$. For two-way ANOVA, the estimated statistical power to detect 50\% augmentation of GH responses to either GHRH or SS pulses by $E_{2}$ during saline or GHRP2 stimulation equaled or exceeded $80 \%$ if 24 women completed the study.

\section{Results}

\section{Subject characteristics at baseline screening}

Epidemiological and baseline endocrine data are given in Table 1. Absolute age range for the 24 participants was 50-76 years. There was no age or BMI difference in the randomized groups (protected $P<0.01$ for multiple tests). Total testosterone, $\mathrm{E}_{2}, \mathrm{LH}, \mathrm{FSH}$, prolactin, SHBG, and TSH concentrations were all normal for age (Mayo Medical Reference Laboratories, Rochester, MN, USA). After $\mathrm{E}_{2}$ vs $\mathrm{Pl}$ supplementation, $\mathrm{E}_{2}(P<0.001)$ and mean GH concentrations during Sal/Sal infusions $(P=0.023)$ and SHBG concentrations $(P<0.01)$ increased, whereas IGF1, IGFBP1, and IGFBP3 concentrations did not change significantly (Table 2 ).

\section{$\mathrm{GH}$ responses to $13-\mathrm{h}$ peptide or saline infusions}

Rapid (3-h) GH responses $>$ The response observed in the first $3 \mathrm{~h}$ of each 13-h peptide/saline infusion session was arbitrarily considered an immediate or rapid response. Analysis of 3-h pulsatile GH secretion revealed strong effects

Table 1 Baseline epidemiological and endocrine data: prerandomization (fasting 0800-h values). Data are means \pm s.E.M. (median, range).

\begin{tabular}{|c|c|c|}
\hline \multirow[b]{2}{*}{ Variables } & \multicolumn{2}{|c|}{ Pre-randomization (fasting $0800-\mathrm{h}$ values) } \\
\hline & $\begin{array}{l}\text { Subsequent placebo } \\
\text { exposure }(n=14)\end{array}$ & $\begin{array}{l}\text { Subsequent } E_{2} \\
\text { exposure }(n=10)\end{array}$ \\
\hline Age (years) & $66 \pm 1.5(66)(55-76)$ & $60 \pm 2.0(60)(50-69)$ \\
\hline $\mathrm{BMI}\left(\mathrm{kg} / \mathrm{m}^{2}\right)$ & $26 \pm 0.85(26)(22-30)$ & $25 \pm 1.1(25)(21-32)$ \\
\hline $\mathrm{Hb}(\mathrm{g} / \mathrm{dl})$ & $13 \pm 0.22(13)(12-15)$ & $13 \pm 0.40$ (14) (12-16) \\
\hline Albumin $(g / d l)$ & $\begin{array}{l}4.3 \pm 0.05(4.3) \\
\quad(3.9-4.6)\end{array}$ & $\begin{array}{l}4.5 \pm 0.05(4.4) \\
\quad(4.2-4.8)\end{array}$ \\
\hline $\begin{array}{l}\text { Total testosterone } \\
(\mathrm{nmol} / \mathrm{l})\end{array}$ & $\begin{array}{l}0.83 \pm 0.13(0.58) \\
\quad(0.26-1.8)\end{array}$ & $\begin{array}{l}0.66 \pm 0.15(0.52) \\
\quad(0.28-1.8)\end{array}$ \\
\hline $\mathrm{E}_{2}(\mathrm{pmol} / \mathrm{l})$ & $69 \pm 12(69)(39-128)$ & $68 \pm 11(81)(35-128)$ \\
\hline LH (IU/I) & $25 \pm 2.6(26)(12-44)$ & $31 \pm 2.0$ (29) (23-43) \\
\hline FSH (IU/l) & $88 \pm 13(75)(41-171)$ & $74 \pm 6.7$ (69) (37-125) \\
\hline Prolactin $(\mu \mathrm{g} / \mathrm{l})$ & $6.1 \pm 0.74(5.5)(3-11)$ & $7.5 \pm 0.56(8.0)(4-9)$ \\
\hline SHBG $(n M)$ & $53 \pm 5.5(48)(31-98)$ & $59 \pm 10(53)(24-136)$ \\
\hline TSH (mU/l) & $\begin{array}{l}1.8 \pm 0.22(1.6) \\
\quad(0.5-3.2)\end{array}$ & $\begin{array}{l}1.8 \pm 0.27(1.5) \\
\quad(0.8-3.1)\end{array}$ \\
\hline
\end{tabular}


Table 2 Baseline epidemiological and endocrine data: postrandomization (mean of six visits per subject). Data are means \pm S.E.M. (median, range).

\begin{tabular}{|c|c|c|}
\hline \multirow[b]{2}{*}{ Variables } & \multicolumn{2}{|c|}{ Post-randomization (mean of six visits per subject) } \\
\hline & During placebo exposure & During $E_{2}$ exposure \\
\hline $\mathrm{E}_{2}(\mathrm{pmol} / \mathrm{l})$ & $66 \pm 13(58)$ & $450 \pm 110(355) *$ \\
\hline IGFBP1 ( $\mu \mathrm{g} / \mathrm{l})$ & $35 \pm 4.6(28)$ & $43 \pm 6.1(42)$ \\
\hline IGFBP3 (mg/l) & $3.6 \pm 0.71(3.5)$ & $3.2 \pm 0.23(3.1)$ \\
\hline IGF1 (nmol/l) & $21 \pm 2.6(18)$ & $17 \pm 2.0(16)$ \\
\hline SHBG (nM) & $42 \pm 4.3(39)$ & $93 \pm 17(91)^{*}$ \\
\hline $\mathrm{GH}(\mu \mathrm{g} / \mathrm{l})$ & $0.48 \pm 0.073(0.42)$ & $0.88 \pm 0.16(0.72)^{a}$ \\
\hline
\end{tabular}

Protected $P<0.01$ vs placebo.

a Mean of 13 -h sampling during Sal/Sal infusions $\left(P=0.023\right.$ for $\mathrm{Pl}$ vs $\mathrm{E}_{2}$ exposure).

of: i) $E_{2}$ vs Pl supplementation ( $\left.P=0.0085\right)$; ii) GHRP2 vs Sal infusion $(P<0.0001)$; iii) GHRH vs Sal infusion $(P<0.0001)$; and iv) GHRH vs SS infusion $(P<0.0001)$ (Table 3, column 1$)$. SS infusion had no significant effect on this end point.

Sustained (10-h) responses to peptide infusions $~$ The response observed in the last $10 \mathrm{~h}$ of each 13-h infusion session was considered a sustained response. Median 10-min GH concentrations ( $\mathrm{Pl}, n=14 ; \mathrm{E}_{2}, n=10$ ) over this interval (2300-0900 h) under saline infusion are shown in green in Fig. 2. GHRH pulses elicited marked pulsatile GH responses (blue lines) in all four major conditions: Pl (no $\mathrm{E}_{2}$ )/Sal, $\mathrm{E}_{2} / \mathrm{Sal}, \mathrm{Pl} / \mathrm{GHRP} 2$, and $\mathrm{E}_{2} / \mathrm{GHRP} 2$. The unique combination of pulses of GHRH and continuous GHRP2 infusions with or without $\mathrm{E}_{2}$ supplementation was maximally stimulatory. SS pulses were inhibitory (red lines) only in the presence of Pl/GHRP2 and $E_{2} / G H R P 2$. Deconvolution analysis revealed significant treatment effects on $10-\mathrm{h}$ pulsatile GH secretion. Figure 3 shows box-and-whisker plots (medians, interquartile ranges, 95\% CIs, and extreme ranges (solid dots)) for the 12 arms: six with Pl supplementation (left panel) and six with $\mathrm{E}_{2}$ supplementation (right panel). Statistical main effects existed for $E_{2}$ $(P=0.054)$, GHRP2 $(P<0.0001)$, and GHRH (vs saline and SS; $P<0.0001$ ) (Table 3 , column 2). SS vs Sal infusion had no effect. There was a prominent amplifying interaction between GHRP2 and GHRH $(P<0.0001)$ and a nonsignificantly trending potentiating interaction between $\mathrm{E}_{2}$ and GHRP2 $(P=0.059)$ for 10 -h pulsatile GH secretion.

\section{ApEn (degree of irregularity)}

The ApEn of GH secretion over the sustained 10-h period of saline or peptide infusions $(2300-0900 \mathrm{~h}$ ) revealed main effects of $\mathrm{E}_{2}(P=0.028)$, continuous GHRP2 $(P<0.0001)$, pulsed GHRH $(P<0.0001)$, and pulsed SS $(P=0.013)$ to increase ApEn (Table 3, column 3). In particular, $\mathrm{E}_{2}$ vs Pl supplementation elevated GH ApEn under Sal/SS $(P<0.001)$ and GHRP2/Sal $(P<0.01)$ infusions, strongly suggesting decreased feedback. Moreover, there were significant interactions between $\mathrm{E}_{2}$ and GHRP2 $(P=0.022)$, between $\mathrm{E}_{2}$ and $\mathrm{GHRH}(P=0.019)$, and among $\mathrm{E}_{2}, \mathrm{GHRP} 2$, and GHRH/SS $(P=0.027)$ in increasing ApEn.

\section{Triple-stimulus effects}

A triple stimulus of consecutive L-arginine and combined GHRP2/GHRH infusion was used to evaluate pituitary GH secretory capacity at the end of the $13-\mathrm{h}$ pulsatile peptide infusion session (Fig. 4). Prior 13-h pulsatile GHRH infusion potentiated pulsatile $\mathrm{GH}$ secretion after the triple stimulus $(P=0.0015)$, whether or not $\mathrm{E}_{2}$ was administered (blue lines in the top two panels). Concomitant GHRP2 infusion (blue lines, bottom two panels) unexpectedly suppressed $(P<0.0001)$ the GHRH effect (bottom two panels). Statistical outcomes are summarized in column 4 of Table 3. Specifically, $\mathrm{E}_{2}$ supplementation increased the GH-inhibitory effect of GHRP2 on GHRH's priming of pulsatile $\mathrm{GH}$ secretion $(P=0.049)$. $\mathrm{E}_{2}$ supplementation did not affect median GH concentrations after GHRH infusion, but it did increase the simple peak GH concentration (arithmetic maximum) response to the triple stimulus following 13-h Sal/SS $(P<0.01)$, GHRP2/Sal $(P<0.05)$, and GHRP2/GHRH $(P<0.05)$ infusions. Comparable median levels but higher peak values after GHRH pretreatment probably reflect the fact that peak values occur at nonuniform time points after the triple stimulus.

Table 3 Pulsatile GH secretion and ApEn in 24 women. Splitplot analysis with main effects and interactions.

\begin{tabular}{|c|c|c|c|c|}
\hline & $\begin{array}{l}\text { Pulsatile } \\
\text { (acute/3 h) }\end{array}$ & $\begin{array}{c}\text { Pulsatile } \\
\text { (sustained/ } \\
10 \mathrm{~h} \text { ) }\end{array}$ & $\begin{array}{c}\text { ApEn } \\
\text { (irregularity) }\end{array}$ & $\begin{array}{c}\text { Pulsatile } \\
\text { after } \\
\text { triple } \\
\text { stimulus }\end{array}$ \\
\hline \multicolumn{5}{|l|}{ Main effects } \\
\hline i) $E_{2}$ & 0.0085 & 0.054 & 0.028 & 0.92 \\
\hline ii) GHRP2 & $<0.0001$ & $<0.0001$ & $<0.0001$ & $<0.0001$ \\
\hline $\begin{array}{l}\text { iii) Pulsed peptides } \\
\text { (GHRH/SS/Sal) }\end{array}$ & $<0.0001$ & $<0.0001$ & $<0.0001$ & 0.0028 \\
\hline GHRH vs Sal & $<0.0001$ & $<0.0001$ & $<0.001$ & 0.0015 \\
\hline SS vs Sal & 0.63 & 0.95 & 0.013 & 0.32 \\
\hline GHRH vs SS & $<0.0001$ & $<0.0001$ & 0.012 & 0.091 \\
\hline \multicolumn{5}{|l|}{ Interactions } \\
\hline $\mathrm{E}_{2} \times \mathrm{GHRP} 2$ & 0.61 & 0.059 & 0.022 & 0.049 \\
\hline $\mathrm{E}_{2} \times \mathrm{GHRH} / \mathrm{SS} / \mathrm{Sal}$ & 0.45 & 0.17 & 0.019 & 0.10 \\
\hline $\begin{array}{l}\text { GHRP2 } 2 \times \text { GHRH/ } \\
\text { SS/Sal }\end{array}$ & 0.091 & $<0.0001$ & 0.31 & 0.55 \\
\hline All three factors & 0.77 & 0.67 & 0.027 & 0.74 \\
\hline
\end{tabular}

Data are $P$ values for main effects and interactions. 


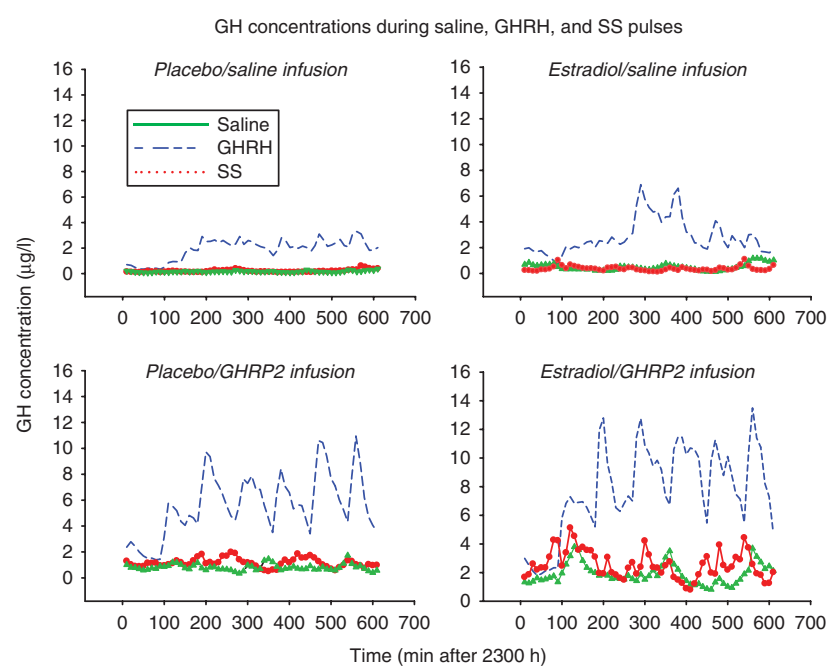

Figure 2

Median GH concentration profiles obtained by sampling blood every $10 \mathrm{~min}$ overnight during the last $10 \mathrm{~h}$ of a $13-\mathrm{h}$ interval (2300-0900 h) of constant saline (top row) or GHRP2 (bottom row) infusions in 14 women treated with placebo (no $E_{2}$ ) (left column) and ten other women treated with $E_{2}$ (right column). The colors green, blue, and red denote superimposed pulsatile infusions of saline, $\mathrm{GHRH}$, and $\mathrm{S}$ respectively. $X$-axis zero time is $2250 \mathrm{~h}$. The corresponding box-and-whisker plots of the matching statistical outcomes are shown in Fig. 3.

\section{Linear regression analysis}

A stepwise backward-elimination multivariate regression analysis was used to explore the effects of BMI, age, $\mathrm{E}_{2}$, IGF1, IGFBP1, and IGFBP3 on GH secretory responses to the overnight peptide infusions and the subsequent triple stimulus. In relation to $10-\mathrm{h}$ data, BMI was a negative correlate of total (basal plus pulsatile) $\mathrm{GH}$ secretion during Sal/GHRH infusions $\left(P=0.006\right.$ and $\left.R^{2}=0.29\right)$ as well as GHRP2/GHRH infusions $\left(P=0.015\right.$ and $\left.R^{2}=0.24\right)$, and $\mathrm{E}_{2}$ was a positive correlate of 10 -h total $\mathrm{GH}$ secretion under GHRP2/Sal infusions $\left(R^{2}=-0.22\right.$ and $\left.P=0.022\right)$. In relation to the triple stimulus, BMI significantly reduced and $\mathrm{E}_{2}$ increased the total GH secretory response after $13 \mathrm{~h}$ of Sal/Sal infusions (joint $P=0.003$ and $R^{2}=0.44$ ) and Sal/GHRH infusions $\left(P=0.013\right.$ and $\left.R^{2}=0.39\right)$. On the other hand, BMI and age together determined the triple-stimulus effect on total GH secretion after $13 \mathrm{~h}$ of combined GHRP2/GHRH infusion $\left(P=0.001\right.$ and $\left.R^{2}=0.46\right)$. BMI negatively predicted $\mathrm{GH}$ responses to the triple stimulus after GHRP2/Sal infusions $\left(P=0.030\right.$ and $\left.R^{2}=0.20\right)$.

\section{Discussion}

The present clinical investigation in postmenopausal women unveils the major effects of $\mathrm{E}_{2}$ supplementation on $\mathrm{GH}$ secretory dynamics driven by an ensemble of GH-regulating peptides, viz. repetitive i.v. pulses of GHRH, SS, and saline with or without continuous GHRP stimulation. Peptide doses were chosen based on prior peptide dose-response curves obtained in older women $(10,11,12)$. The salient effects of $E_{2}$ were as follows: i) amplification of rapid (initial 3-h) pulsatile GH secretion during overnight pulsatile Sal/GHRH stimulation $(P=0.0085)$, with a strong analogous trend for $\mathrm{E}_{2}$ to augment prolonged (10-h) pulsatile GH secretion during GHRP2 drive $(P=0.059)$, signifying a greater mass of $\mathrm{GH}$ released per burst; ii) elevation of GH ApEn during GHRP2 $(P=0.022)$ and SS $(P<0.001)$ infusions, thus suggesting decreased feedback effects under $\mathrm{E}_{2}$ supplementation; and iii) opposition in an $\mathrm{E}_{2}$ concentration-dependent manner the negative effect of BMI on the GH secretory response to a massive triple stimulus. The last point becomes relevant for interpreting pharmacological testing of GH reserve capacity (8), suggesting that

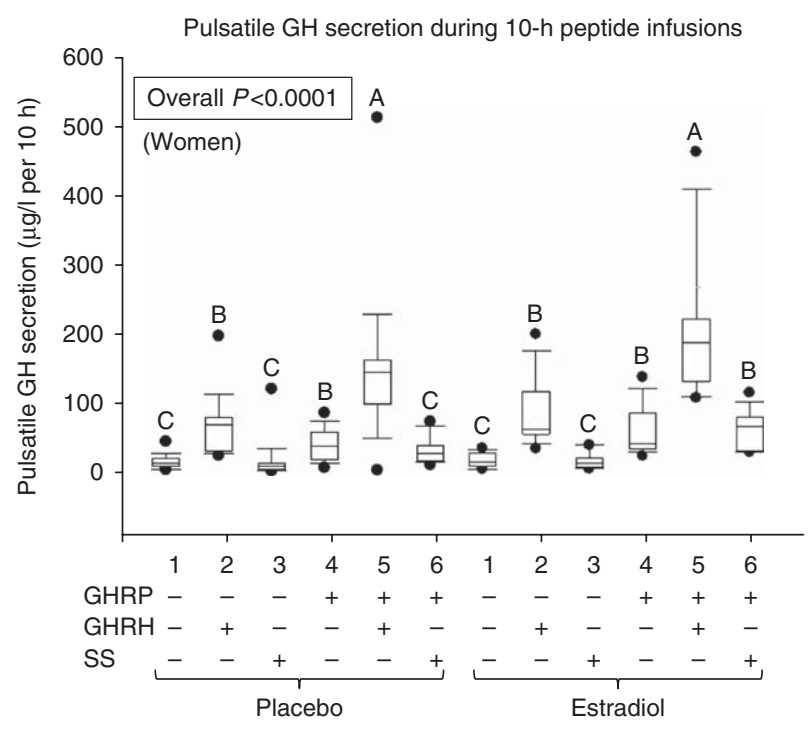

\section{Figure 3}

Box-and-whisker plots of 10-h pulsatile GH secretion. Data are medians, interquartile ranges, $95 \% \mathrm{Cls}$, and extreme ranges (separate dots). Fourteen women were randomized to receive placebo (six bars on the left) and ten women $E_{2}$ (six bars on the right) for 20 days. The general linear model $P$ value was $<0.0001$. Boxes with unique (unshared) alphabetic superscripts differ significantly by post hoc Tukey's HSD multiple-comparison test (e.g. A differs from $B$ and $C$, but not from $A B$ ). 


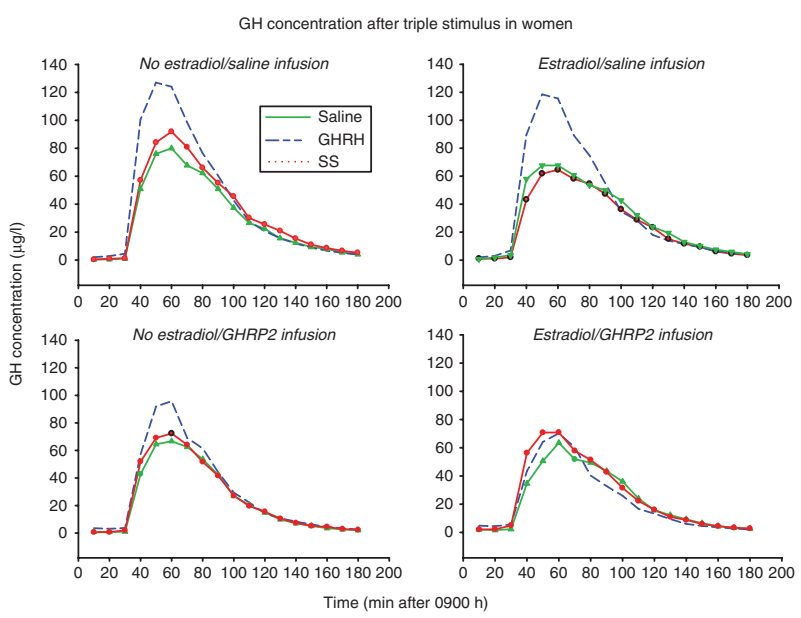

Figure 4

Median GH concentration profiles obtained by sampling blood every $10 \mathrm{~min}$ over $3 \mathrm{~h}(0900-1200 \mathrm{~h}$ ) during (0900-0930 h) and following (0930-1200 h) the triple stimulus (Fig. 1).

both BMI and $\mathrm{E}_{2}$ administration may alter the cutoffs for a maximal GH response at least in older women.

GH regulation is important in aging, in as much as small increments in GH availability in older adults decrease visceral adiposity, diastolic blood pressure, and LDL concentrations and increase lean body mass (19). Pulsatile secretion is a key locus of physiological GH regulation by hypothalamo-pituitary GHRH, SS, and GHRP $(2,20)$. In turn, GH pulses specifically control liver and muscle gene expression, mediate GH feedback on brain, and enhance lipolysis in fat (3). Thus, tissue responses to GH peaks may be more significant than those to mean/median GH concentrations per se, especially in relation to growth and anabolism (3). The generation of GH pulses is believed to require SS, GHRH, and GHRP/ghrelin. First, SS withdrawal seems necessary before GHRH pulses can initiate prominent GH secretory bursts $(3,20,21)$. Second, GHRH is essential for stimulating both $\mathrm{GH}$ release and $\mathrm{GH}$ synthesis (2). SS and GHRH act in concert, since SS restrains exocytosis (but not synthesis) of $\mathrm{GH}$, thus allowing the accumulation of releasable GH stores under ongoing GHRH-stimulated GH synthesis (14). Third, whereas GHRP does not augment GH synthesis, it markedly potentiates GHRH-evoked GH release, thus serving as an in vivo amplifier of GH pulsatility $(3,22,23,24)$. We tested the amplifying interaction between GHRH and GHRP by infusing GHRH pulses every 90 min for $13 \mathrm{~h}$ along with saline or GHRP2. GHRP2 and a physiologically pulsatile GHRH stimulus were strongly synergistic over $10 \mathrm{~h}$ independently of $\mathrm{E}_{2}$ availability. The importance of GHRH for maximal GHRP drive has been established in patients with inactivating mutations of the GHRH receptor (21) or hypothalamo-pituitary disconnection (23). Thus, a working model of GH pulsatility would include SS as a determinant of the timing and size of GH secretory bursts and ghrelin/GHRP and GHRH as individual and synergistic amplifiers of the size of GH pulses $(20,25,26,27,28)$.

SS is a powerful inhibitor of GH release. In the presence of $E_{2}$, repeated SS pulses increased GH ApEn (Table 3), a statistical measure of the relative randomness, irregularity, or disorderliness of secretory patterns (29). The ability of $\mathrm{E}_{2}$ and SS to increase GH ApEn would be consistent with the ability of $\mathrm{E}_{2}$ to attenuate GH and IGF1 feedback and SS potency, as well as to enhance submaximal GHRH and GHRP stimulation in women $(3,10,23,30)$. Nonetheless, SS pulses at the dose used in the present study in women had no detectable effect on GH ApEn in an earlier study in older men in the presence and absence of supplemental testosterone (31). This raises the question whether pituitary sensitivity to SS differs by gender in humans.

The triple-secretagogue paradigm has been suggested as a probe of age-independent $\mathrm{GH}$ release (8). In the present study, we used it to rule out possible ceiling effects of the double-peptide clamps. The average peak GH concentration after the triple stimulus in the present study was $339 \pm 53$ (146-648 range) $\mu \mathrm{g} / \mathrm{l}$ after overnight pulsatile Sal/GHRH infusions. This excluded the downregulation of GH secretion under the overnight GHRH clamp, rather showing the GHRH priming effect. In the combined group of 24 women, $\mathrm{E}_{2}$ concentrations positively determined the peak GH response to the triple stimulus after exposure to $\mathrm{Sal} / \mathrm{Sal}$ and $\mathrm{Sal} / \mathrm{GHRH}$, indicating a selective influence of $\mathrm{E}_{2}$ on GHRH's priming of acute $\mathrm{GH}$ secretion.

When continuous GHRP2 stimulation was combined with a train of GHRH pulses, GHRH's potentiating effect on the acute triple stimulus was suppressed by more than $50 \%$. This was unexpected. The attenuation of the triplesecretagogue effect by GHRP2 could be due, in principle, to homologous GHRP receptor desensitization or heterologous GHRP/GHRH receptor downregulation, as reported in animal models (32). Since heterologous GHRH/GHRP receptor upregulation also occurs, our results introduce the clinical question: what determines GHRH/GHRP up- vs downregulation? The present data further indicate that $\mathrm{E}_{2}$ increases the negative effect of GHRP2 on GHRH's amplification of the triple stimulus. Since $\mathrm{E}_{2}$ elevates $\mathrm{GH}$ levels, high GH concentrations may have exerted negative feedback by hypothalamic SS (20). Nonetheless, L-arginine, as 
part of the triple stimulus used in the present study, would be predicted to mute GH negative feedback $(2,3,33)$.

The significance of this study is that target tissues responded to circulating GH in a pulse-defined and concentration-dependent fashion (2). Complexity arises, since $\mathrm{E}_{2}$ can both inhibit and augment GH's actions on target tissues (e.g. on liver, brain, breast, fat, or bone) (34). The tendency of IGF1 levels to decrease during $\mathrm{E}_{2}$ administration, especially orally, may constitute another mechanism for amplified pulsatile GH secretion beyond that of muting dose-dependent IGF1 feedback actions (30). The joint capabilities of $\mathrm{E}_{2}$ to drive pulsatile patterns of $\mathrm{GH}$ production and to modulate GH's actions on target tissues should confer precise metabolic and anabolic effects. This may be particularly important clinically in otherwise estrogen-deprived women, who are secondarily relatively GH deficient as well.

BMI was a major and consistently negative determinant of total (pulsatile plus basal) GH secretion during pulsatile Sal/GHRH infusions and after triple-secretagogue stimulation. During overnight pulsatile GHRH infusion, BMI (negatively) accounted for $29 \%$ of the variance in total GH secretion. The negative and positive effects of $\mathrm{BMI}$ and $\mathrm{E}_{2}$ together explained $44 \%$ of inter-subject variability in triple stimulus-driven total GH secretion after Sal/Sal infusions. BMI also interacted with age reciprocally in controlling $46 \%$ of the variance in the triple-stimulus effect after combined GHRH/GHRP priming. Thus, even pharmacological multi-stimuli tests of GH secretory reserve are damped by relative obesity. Further studies are needed to test the reproducibility of, and elucidate the exact bases for, these unique interactions.

Limitations include the ultimate need to: elucidate the dose dependence and long-term sustainability of $E_{2}$ effects on multiple peptide-regulated $\mathrm{GH}$ secretion; examine a wide range of pulsed SS and GHRH doses; assess possible effects on sleep as well as GH; and extend the short-term (weeks) paradigm to long-term (months) hormone-replacement regimens.

In summary, controlled $\mathrm{E}_{2}$ supplementation in postmenopausal women exerts positive multipathway effects on GHRH/GHRP/SS-regulated GH secretion. $\mathrm{E}_{2}$ also counteracts the suppressive effect of BMI on stimulated GH secretion. These outcomes suggest multiple loci of estrogenic regulation of the adult female GH axis, viewed as an ensemble of GHRH, GHRP/ghrelin, and SS signals.

Declaration of interest

Dr Dana Erickson is on the Advisory board for Ipsen. Otherwise, the authors have nothing to disclose.
Funding

This study was supported in part via R01 AG029362, P30 DK050456 (Metabolic Studies Core of the Minnesota Obesity Center) from the National Institutes of Health (Bethesda, MD, USA), and UL1 TR000135 from the National Center for Advancing Translational Sciences. Contents are solely the responsibility of the authors and do not necessarily represent the official views of any federal agency.

\section{Author contribution statement}

C Norman carried out the experiments, drafted the manuscript, and approved the final version of the manuscript; N L Rollene, D Erickson, and $\mathrm{J} M$ Miles carried out the experiments and approved the final version of the manuscript; CY Bowers was responsible for the conception and design of the research, interpreted the results of the experiments, and approved the final version of the manuscript; J D Veldhuis was responsible for the conception and design of the research, carried out the experiments, analyzed the data, interpreted the results of the experiments, prepared the figures, revised the manuscript, edited and revised the manuscript, and approved the final version of the manuscript.

\section{Acknowledgements}

The authors thank Jill Smith for support with manuscript preparation and graphics, the Mayo Immunochemical Laboratory for assistance in assays, and the Mayo CRU research nursing staff for implementation of the protocol.

\section{References}

1 Carlson HE, Gillin JC, Gorden P \& Snyder F. Absence of sleep-related growth hormone peaks in aged normal subjects and in acromegaly. Journal of Clinical Endocrinology and Metabolism 197234 1102-1105. (doi:10.1210/jcem-34-6-1102)

2 Giustina A \& Veldhuis JD. Pathophysiology of the neuroregulation of growth hormone secretion in experimental animals and the human. Endocrine Reviews 199819 717-797. (doi:10.1210/er.19.6.717)

3 Veldhuis JD, Roemmich JN, Richmond EJ \& Bowers CY. Somatotropic and gonadotropic axes linkages in infancy, childhood, and the puberty-adult transition. Endocrine Reviews 200627 101-140. (doi:10.1210/er.2005-0006)

4 Frantz AG \& Rabkin MT. Effects of estrogen and sex difference on secretion of human growth hormone. Journal of Clinical Endocrinology and Metabolism 196525 1470-1480. (doi:10.1210/jcem-25-11-1470)

5 Shah N, Evans WS \& Veldhuis JD. Actions of estrogen on the pulsatile, nyctohemeral, and entropic modes of growth hormone secretion. American Journal of Physiology. Regulatory, Integrative and Comparative Physiology 1999276 R1351-R1358.

6 Cosma M, Bailey JN, Miles JM, Bowers CY \& Veldhuis JD. Pituitary and/or peripheral estrogen-receptor $\alpha(\mathrm{ER} \alpha)$ regulates FSH secretion whereas central pathways direct $\mathrm{GH}$ and prolactin secretion in postmenopausal women. Journal of Clinical Endocrinology and Metabolism 200893 951-958. (doi:10.1210/jc.2007-1322)

7 Yan M, Jones ME, Hernandez M, Liu D, Simpson ER \& Chen C. Functional modification of pituitary somatotropes in the aromatase knockout mouse and the effect of estrogen replacement. Endocrinology 2004145 604-612. (doi:10.1210/en.2003-0646)

8 Arvat E, Ceda GP, Di Vito L, Ramunni J, Gianotti L \& Ghigo E. Agerelated variations in the neuroendocrine control, more than impaired receptor sensitivity, cause the reduction in the GH-releasing activity of GHRP's in human aging. Pituitary 19981 51-58. (doi:10.1023/ A:1009970909015) 
9 Erickson D, Keenan DM, Mielke K, Bradford K, Bowers CY, Miles JM \& Veldhuis JD. Dual secretagogue drive of burst-like growth hormone secretion in postmenopausal compared with premenopausal women studied under an experimental estradiol clamp. Journal of Clinical Endocrinology and Metabolism 200489 4746-4754. (doi:10.1210/ jc.2004-0424)

10 Bray MJ, Vick TM, Shah N, Anderson SM, Rice LW, Iranmanesh A, Evans WS \& Veldhuis JD. Short-term estradiol replacement in postmenopausal women selectively mutes somatostatin's dosedependent inhibition of fasting growth hormone secretion. Journal of Clinical Endocrinology and Metabolism 200186 3143-3149. (doi:10.1210/ jc.86.7.3143)

11 Veldhuis JD, Evans WS \& Bowers CY. Estradiol supplementation enhances submaximal feed-forward drive of growth hormone (GH) secretion by recombinant human GH-releasing hormone-1,44-amide in a putatively somatostatin-withdrawn milieu. Journal of Clinical Endocrinology and Metabolism 200388 5484-5489. (doi:10.1210/ jc.2003-030410)

12 Anderson SM, Shah N, Evans WS, Patrie JT, Bowers CY \& Veldhuis JD. Short-term estradiol supplementation augments growth hormone (GH) secretory responsiveness to dose-varying GH-releasing peptide infusions in healthy postmenopausal women. Journal of Clinical Endocrinology and Metabolism 200186 551-560. (doi:10.1210/jc.86.2.551)

13 Khosla S, Amin S, Singh RJ, Atkinson EJ, Melton LJ III \& Riggs BL. Comparison of sex steroid measurements in men by immunoassay versus mass spectroscopy and relationships with cortical and trabecular volumetric bone mineral density. Osteoporosis International 200819 1465-1471. (doi:10.1007/s00198-008-0591-5)

14 Stachura ME, Tyler JM \& Farmer PK. Combined effects of human growth hormone (GH)-releasing factor-44 (GRF) and somatostatin (SRIF) on post-SRIF rebound release of GH and prolactin: a model for GRF-SRIF modulation of secretion. Endocrinology 1988123 1476-1482. (doi:10.1210/endo-123-3-1476)

15 Faria AC, Veldhuis JD, Thorner MO \& Vance ML. Half-time of endogenous growth hormone (GH) disappearance in normal man after stimulation of GH secretion by GH-releasing hormone and suppression with somatostatin. Journal of Clinical Endocrinology and Metabolism 1989 68 535-541. (doi:10.1210/jcem-68-3-535)

16 Keenan DM, Roelfsema F, Biermasz N \& Veldhuis JD. Physiological control of pituitary hormone secretory-burst mass, frequency and waveform: a statistical formulation and analysis. American Journal of Physiology. Regulatory, Integrative and Comparative Physiology 2003285 R664-R673. (doi:10.1152/ajpregu.00195.2003)

17 Veldhuis JD, Straume M, Iranmanesh A, Mulligan T, Jaffe CA, Barkan A, Johnson ML \& Pincus SM. Secretory process regularity monitors neuroendocrine feedback and feedforward signaling strength in humans. American Journal of Physiology. Regulatory, Integrative and Comparative Physiology 2001280 R721-R729.

18 O'Brien PC. The appropriateness of analysis of variance and multiplecomparison procedures. Biometrics 198339 787-794. (doi:10.2307/ 2531110)

19 Ahmad AM, Hopkins MT, Thomas J, Ibrahim H, Fraser WD \& Vora JP. Body composition and quality of life in adults with growth hormone deficiency; effects of low-dose growth hormone replacement. Clinical Endocrinology 200154 709-717. (doi:10.1046/j.1365-2265.2001.01275.x)

20 Mueller EE, Locatelli V \& Cocchi D. Neuroendocrine control of growth hormone secretion. Physiological Reviews 199979 511-607. (doi:10.1111/j.1651-2227.1989.tb17175.x)

21 Roelfsema F, Biermasz NR, Veldman RG, Veldhuis JD, Frolich M, Stokvis-Brantsma WH \& Wit J-M. Growth hormone (GH) secretion in patients with an inactivating defect of the GH-releasing hormone (GHRH) receptor is pulsatile: evidence for a role for non-GHRH inputs into the generation of GH pulses. Journal of Clinical Endocrinology and Metabolism 200186 2459-2464. (doi:10.1210/jc.86.6.2459)

22 Hataya Y, Akamizu T, Takaya K, Kanamoto N, Ariyasu H, Saijo M, Moriyama K, Shimatsu A, Kojima M, Kangawa K et al. A low dose of ghrelin stimulates growth hormone $(\mathrm{GH})$ release synergistically with GH-releasing hormone in humans. Journal of Clinical Endocrinology and Metabolism 200186 4552. (doi:10.1210/jc.86.9.4552)

23 Popovic V, Damjanovic S, Micic D, Djurovic M, Dieguez C \& Casanueva FF. Blocked growth hormone-releasing peptide (GHRP-6)induced GH secretion and absence of the synergistic action of GHRP-6 plus GH-releasing hormone in patients with hypothalamopituitary disconnection: evidence that GHRP-6 main action is exerted at the hypothalamic level. Journal of Clinical Endocrinology and Metabolism 199580 942-947. (doi:10.1210/jc.80.3.942)

24 Vale WW, Vaughan J, Yamamoto G, Spiess J \& Rivier J. Effects of synthetic human pancreatic (tumor) GH releasing factor and somatostatin, triiodothyronine and dexamethasone on GH secretion in vitro. Endocrinology 1983112 1553-1555. (doi:10.1210/endo-112-4-1553)

25 Farhy LS \& Veldhuis JD. Deterministic construct of amplifying actions of ghrelin on pulsatile GH secretion. American Journal of Physiology. Regulatory, Integrative and Comparative Physiology 2005288 R1649-R1663. (doi:10.1152/ajpregu.00451.2004)

26 Guillaume V, Magnan E, Cataldi M, Dutour A, Sauze N, Renard M, Razafindraibe H, Conte-Devolx B, Deghenghi R \& Lenaerts V. Growth hormone (GH)-releasing hormone secretion is stimulated by a new GH-releasing hexapeptide in sheep. Endocrinology 1994135 1073-1076. (doi:10.1210/en.135.3.1073)

27 Chihara K, Minamitani N, Kaji H, Arimura A \& Fujita T. Intraventrically injected growth hormone stimulates somatostatin release into rat hypophyseal portal blood. Endocrinology 1981109 2279-2281. (doi:10.1210/endo-109-6-2279)

28 Miki N, Ono M \& Shizume K. Withdrawal of endogenous somatostatin induces secretion of growth hormone-releasing factor in rats. Journal of Endocrinology 1988117 245-252. (doi:10.1677/joe.0.1170245)

29 Pincus SM \& Singer BH. Randomness and degrees of irregularity. PNAS 199693 2083-2088. (doi:10.1073/pnas.93.5.2083)

30 Veldhuis JD, Keenan DM, Bailey JN, Adeniji A, Miles JM, Paulo R \& SoaresWelch C. Estradiol supplementation in postmenopausal women attenuates suppression of pulsatile growth-hormone secretion by recombinant human insulin-like growth factor type I. Journal of Clinical Endocrinology and Metabolism 200893 4471-4478. (doi:10.1210/jc.2008-1493)

31 Norman C, Miles JM, Bowers CY \& Veldhuis JD. Differential pulsatile secretagogue control of GH secretion in healthy men. American Journal of Physiology. Regulatory, Integrative and Comparative Physiology 2013304 R712-R719. (doi:10.1152/ajpregu.00069.2013)

32 Luque RM, Kineman RD, Park S, Peng XD, Gracia-Navarro F, Castano JP $\&$ Malagon MM. Homologous and heterologous regulation of pituitary receptors for ghrelin and growth hormone-releasing hormone (GHRH). Endocrinology 2004145 3182-3189. (doi:10.1210/en.2003-1626)

33 Gianotti L, Maccario M, Lanfranco F, Ramunni J, Di Vito L, Grottoli S, Mueller EE, Ghigo E \& Arvat E. Arginine counteracts the inhibitory effect of recombinant human insulin-like growth factor I on the somatotroph responsiveness to growth hormone-releasing hormone in humans. Journal of Clinical Endocrinology and Metabolism 200085 3604-3608. (doi:10.1210/jc.85.10.3604)

34 Leung KC, Johannsson G, Leong GM \& Ho KK. Estrogen regulation of growth hormone action. Endocrine Reviews 200425 693-721. (doi:10.1210/er.2003-0035)

Received 6 September 2013

Revised version received 8 October 2013

Accepted 10 October 2013 